\title{
Identification and Analytical Characterization of a Novel Synthetic Cannabinoid-Type Substance in Herbal Material in Europe
}

\author{
Emmanouil D. Tsochatzis ${ }^{1,2}$, Joao Alberto Lopes ${ }^{1, *}$, Margaret V. Holland ${ }^{1}$, Fabiano Reniero ${ }^{1}$, Giovanni Palmieri ${ }^{3}$ \\ and Claude Guillou ${ }^{1, *}$ \\ 1 European Commission, Joint Research Centre, Via E. Fermi 2749, TP 281, I-21020 Ispra (VA), Italy; \\ Emmanouil.TSOCHATZIS@ec.europa.eu (E.D.T.); Margaret.HOLLAND@ec.europa.eu (M.V.H.); \\ Fabiano.RENIERO@ec.europa.eu (F.R.) \\ 2 Department of Food Science, Aarhus University, Agro Food Park 48, 8200 Aarhus N, Denmark \\ 3 Agenzia Dogane Monopoli, Direzione Regionale per la Lombardia, Laboratorio e Servizi Chimici, \\ 20138 Milan, Italy; giovanni.palmieri01@agenziadogane.it \\ * Correspondence: Joao-Filipe.ALBERTO-LOPES@ec.europa.eu (J.A.L.); \\ Claude.GUILLOU@ec.europa.eu (C.G.); Tel.: +39-0332-785678 (C.G.)
}

Citation: Tsochatzis, E.D.; Alberto Lopes, J.; Holland, M.V.; Reniero, F.; Palmieri, G.; Guillou, C. Identification and Analytical Characterization of a Novel Synthetic Cannabinoid-Type Substance in Herbal Material in Europe. Molecules 2021, 26, 793. https://doi.org/10.3390/molecules 26040793

Academic Editor: Jih-Jung Chen Received: 30 December 2020 Accepted: 1 February 2021 Published: 3 February 2021

Publisher's Note: MDPI stays neutral with regard to jurisdictional claims in published maps and institutional affiliations.

Copyright: (c) 2021 by the authors. Licensee MDPI, Basel, Switzerland. This article is an open access article distributed under the terms and conditions of the Creative Commons Attribution (CC BY) license (https:/ / creativecommons.org/licenses/by/ $4.0 /)$.

\begin{abstract}
The rapid diffusion of new psychoactive substances (NPS) presents unprecedented challenges to both customs authorities and analytical laboratories involved in their detection and characterization. In this study an analytical approach to the identification and structural elucidation of a novel synthetic cannabimimetic, quinolin-8-yl-3-[(4,4-difluoropiperidin-1-yl) sulfonyl]4-methylbenzoate (2F-QMPSB), detected in seized herbal material, is detailed. An acid precursor 4-methyl-3-(4,4-difluoro-1-piperidinylsulfonyl) benzoic acid (2F-MPSBA), has also been identified in the same seized material. After extraction from the herbal material the synthetic cannabimimetic, also referred to as synthetic cannabinoid receptor agonists or "synthetic cannabinoids", was characterized using gas chromatography-mass spectrometry (GC-MS), ${ }^{1} \mathrm{H},{ }^{13} \mathrm{C},{ }^{19} \mathrm{~F}$ and ${ }^{15} \mathrm{~N}$ nuclear magnetic resonance (NMR) and high-resolution tandem mass spectrometry (HR-MS/MS) combined with chromatographic separation. A cheminformatics platform was used to manage and interpret the analytical data from these techniques.
\end{abstract}

Keywords: synthetic cannabinoids; 2F-QMPSB; HR-MS/MS; NMR; GC-MS; cheminformatics

\section{Introduction}

Recent studies have reported a significant increase in the number of novel psychoactive substances (NPS) within the EU recreational drug market [1-6]. Currently synthetic cannabinoids form the largest group of NPS being monitored by the European Monitoring Centre for Drugs and Drug Addiction (EMCDDA), with as many as 160 detected in Europe since 2008 [1]. Synthetic cannabinoids function as high efficacy CB1 and/or CB2 cannabinoid receptor agonists, in contrast with the low to moderate efficacy of tetrahydrocannabinol (THC), the main psychoactive component of cannabis [6-11]. 8-quinolinyl-4methyl-3-(1-piperidinylsulfonyl) benzoate (QMPSB), was detected in Australia between 2011 and 2012 [9] and is reported to be active in the low nanomolar range as a full agonist of the CB1 receptor [12]. The binding affinity of QMPSB, which was evaluated on the basis of $\left[{ }^{3} \mathrm{H}\right]-\mathrm{CP}-55940$ binding to membranes of HEK cells, expressing human CB1 and CB2 receptors, is reported as $\mathrm{Ki}(\mathrm{CB} 1)=3 \mathrm{nM}$ and $\mathrm{Ki}(\mathrm{CB} 2)=4 \mathrm{nM}$. According to this study, QMPSB behaves as a highly potent, poorly selective, dual CB1 and CB2 agonist [13].

The evolution of the EU market for NPS, and the speed at which new substances are being created, gives cause for concern. The authorities are struggling to keep up with the surge in these substances of abuse. Moreover, their accessibility via the internet, e-shops and social-networking sites, where they are often mislabeled as "bath salts" or "herbal 
extracts", plays a major role in their marketing, sale and distribution. An example of this was seen in the seizure of plant material containing QMPSB, which was packaged and labeled as herbal incense [9-20]. Many attempts have been made to try to reduce the production of such products, also marketed as potpourri, herbal tea or "Spice", and all containing synthetic cannabinoids [9,19].

EU customs authorities are responsible for collecting and safeguarding customs duties, as well as controlling the flow of goods into, and out of, the EU, often acting as the first contact point for NPS as they reach Europe via its various borders (maritime, air and terrestrial) [6,21]. The customs laboratories generally perform routine analysis, using techniques such as GC-MS and FT-IR, to identify seized substances, usually relying on matches with results already available in spectral libraries [21]. However, advanced analytical tools such as nuclear magnetic resonance (NMR) and high-resolution liquidchromatography tandem mass-spectrometry (HR-LC-MS/MS) are often also required for the complete identification of the chemical structure of new substances. In previous studies we have described our integrated workflow, combining data from the standard analytical techniques (GC-MS, FT-IR) used in customs laboratories with further analysis using NMR and HR-MS, performed at the European Commission's Joint Research Centre (JRC) in Ispra, Italy. This approach enabled the rapid identification of several NPS and contributed to the successive search for information about them [22].

The current study presents the application of this workflow to the chemical characterization of the new synthetic cannabinoid 2F-QMPSB (quinolin-8-yl 3-((4,4-difluoropiperidin1-yl)sulfonyl)-4-methylbenzoate) (Figure S1), which was identified in three different samples of herbal material (hereafter identified as samples 7,8 and 9) which were found, together with several other synthetic cannabinoids, in a postal parcel seized by customs control authorities (see Section 4.2 Seized herbal material samples). Subsequent to its identification, 2F-QMPSB was formally notified to the EMCDDA on the 9 January 2019 [23]. Here we also present additional data on the analytical characterisation of 2F-QMPSB which led to the identification of a secondary compound, 2F-MPSBA (3-(4,4-difluoropiperidine-1sulfonyl)-4-methylbenzoic acid)) (Figure S2), which had not yet been identified at the time of notification to the EMCDDA.

\section{Results}

\subsection{GC-MS Analysis}

The qualitative analysis performed using GC-IT-MS (Gas Chromatography-Ion TrapMass Spectrometry) of the herbal material methanol extract, carried out by the Italian customs laboratory, revealed two chromatographic peaks at $t_{R}=5.38$ min and at $t_{R}=17.54 \mathrm{~min}$. The obtained results were further analyzed with the cheminformatics platform ACD/Spectrus and the obtained chromatogram, along with the resulting mass spectra, are presented in Figure 1. An additional chloroform extract of the same herbal material was performed at the JRC and analysed using GC-MS.

From the GC-IT-MS spectrum analysis of the methanol extract it could be seen that two compounds were present. Through peak picking analysis and interpretation of the mass spectra using the ACD/Spectrus algorithms, it was revealed that the peak at $t_{R}=17.54 \mathrm{~min}$ refers to the potential synthetic cannabinoid-type substance 2F-QMPSB and the peak at $t_{R}=5.38$ min initially looked as if it could be 4,4-difluoropiperidine $(\mathrm{m} / \mathrm{z} 121)$. However, after further processing of the results it was confirmed that only the peak at $m / z 120$ was correlated with this structure, while there was an abundant fragment at $m / z 149$ which was not representative of 4,4-difluoropiperidine. It was found that this substance seemed to be the methylated product of 2F-MPSBA [4-methyl-3-(4,4-difluoro-1-piperidinylsulfonyl) benzoic acid], an acid precursor of 2F-QMPSB (Figure 1C,D). However, this was not identified in the chloroform extract, which suggests that a transesterification reaction occurred during the extraction of the herbal material with methanol (Figure 1A,B). In fact, Blakey et al. already highlighted in their work that these analytical artifacts can occur due to both extraction and/or analysis using GC-MS of synthetic cannabinoids extracted 
from plant material [9]. These results may indicate the presence of the acid version of that substance in the herbal material that is coextracted with the cannabinoid. Its absence in the GC-MS analysis of the chloroform extract is explained by the analytical column used (DB5-MS), which has a stationary phase that is not suited to the analysis of acids. This can be further explained by the fact that the volatility of this substance is probably lower than that of the cannabinoid itself.

All the identified fragments for both substances, including formulas and mass differences (Da), are presented in Table S1 as produced by the ACD/Labs platform. Using the area normalisation approach, a ratio of 3:7 was estimated for the methylated precursor-tocannabinoid areas in the GC-IT-MS TIC.
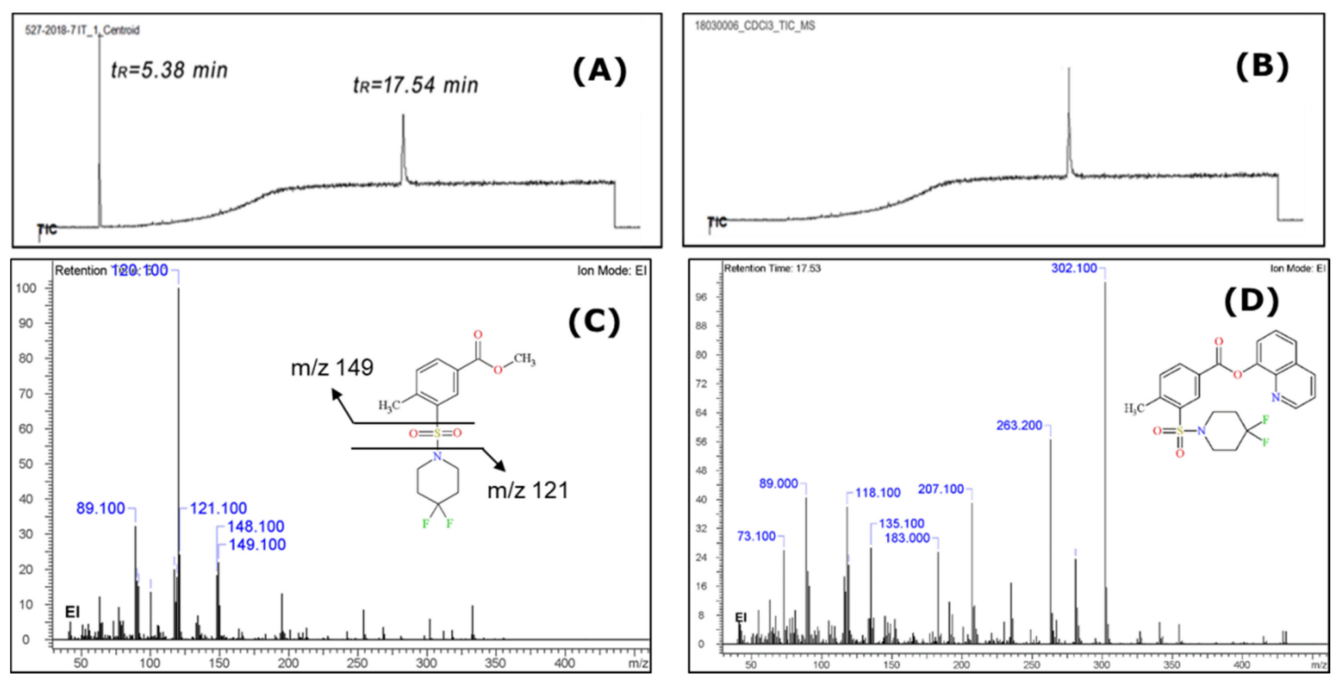

Figure 1. GC total ion chromatogram (Scan mode) of the methanol extract (A), chloroform extract (B) and EI-MS spectra of the identified methylated precursor of 2F-MPSBA in the methanol extract $\left(t_{R}=5.38 \mathrm{~min}\right)(C)$ and the identified synthetic cannabinoid $2 \mathrm{~F}-\mathrm{QMPSB},\left(\mathrm{t}_{\mathrm{R}}=17.54 \mathrm{~min}\right)(\mathrm{D})$.

\subsection{NMR Analysis}

The NMR spectra recorded for the $\mathrm{CDCl}_{3}$ extracts showed broad signals at between 0 and $1.8 \mathrm{ppm}$, which can be attributed to the lipidic fraction extracted from the herbal material (Figure S5). The NMR spectra of the three samples, 7, 8 and 9, also showed similar patterns of signals corresponding to aliphatic chains and aromatic protons whose relative proportions seemed to indicate the presence of two major compounds (Figure S6). For the three samples, the ${ }^{19} \mathrm{~F}$ NMR spectra also showed a signal indicating the presence of fluorine in the unknown substances investigated (Figure S7). Initially the chemical shifts and overlaps observed for the signals in the aromatic region made it rather difficult to achieve a clear and full interpretation of the spectra in $\mathrm{CDCl}_{3}$. However, the spectra obtained for the same extracts, redissolved in DMSO- $\mathrm{d}_{6}$, showed a better resolution of the signals, in particular in the aromatic region (See Figure 2, Figures S8 and S9). In contrast with the spectra in $\mathrm{CDCl}_{3}$, the chemical shifts observed for the major signals remain almost constant for all three samples independently of the relative proportions of the two main components (Figure S9).

The ${ }^{1} \mathrm{H}$ NMR spectrum showing 2F-QMPSB and 2F-MPSBA, is presented, with particular focus on the "aromatic region" of the spectrum, in Figure 2. The ${ }^{1} \mathrm{H} \mathrm{NMR},{ }^{13} \mathrm{C}$ and ${ }^{3} \mathrm{~J}_{\mathrm{HH}}$ coupling constants (Table 1 ) for the identified compounds are consistent with those reported by Blakey, et al. [9]. More specifically, the chemical shifts observed for the piperidinyl unit, in both the ${ }^{1} \mathrm{H}$ and the ${ }^{13} \mathrm{C}$ NMR spectra (Figure 3), are in accordance with those from both Blakey, et al. and Uchiyama, et al. [9,24]. The identified molecule has a very similar structure to QMPSB with the only difference being due to the presence of two fluorine atoms in position $4^{\prime}$ of the piperidinyl group. Additional results obtained 
with both monodimensional and bidimensional NMR are presented in the Supplementary Materials: COSY (Figure S11), HSQC-DEPT (Figure S10), HMBC ${ }^{15} \mathrm{~N}-{ }^{1} \mathrm{H}$ (Figure S12), HMBC ${ }^{13} \mathrm{C}-{ }^{1} \mathrm{H}$ (Figure S13), TOCSY (Figure S14) and ${ }^{19} \mathrm{~F}$ NMR (Figure S7).
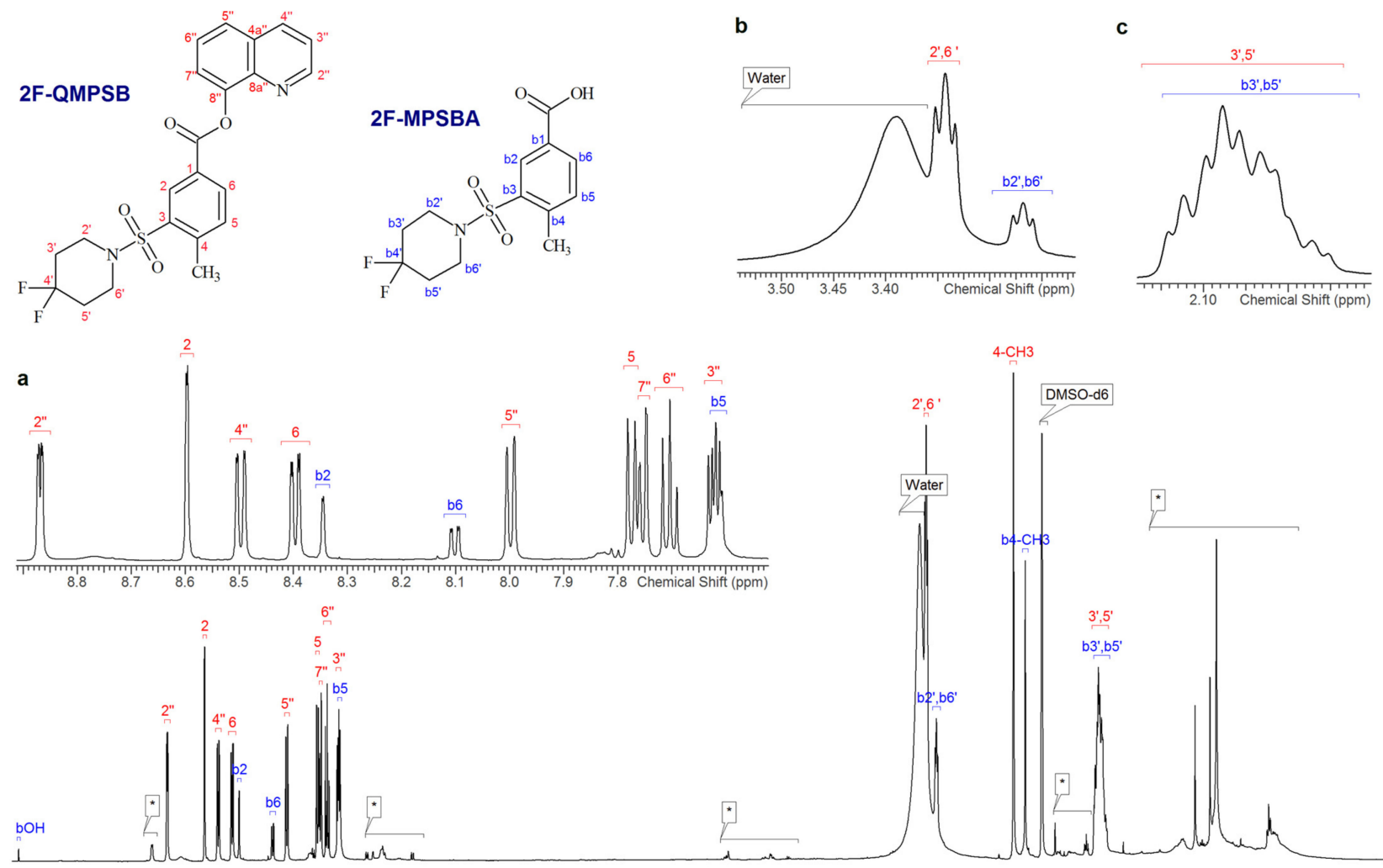

$$
\text { एलग1 } 9.5
$$

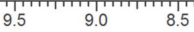

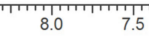

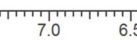

Figure 2. ${ }^{1} \mathrm{H}$ NMR spectrum of sample 9 in DMSO- $\mathrm{d}_{6}$ with expansions of (a) the aromatic region (b) and (c) the aliphatic region. The signals annotated with an asterisk $\left(^{*}\right)$ are from other unidentified species extracted from the matrix.

Table 1. ${ }^{1} \mathrm{H}$ and ${ }^{13} \mathrm{C}$ NMR peak assignments and coupling constants for 2F-QMPSB.

\begin{tabular}{ccccc}
\hline Carbon & $\boldsymbol{\delta}^{\mathbf{1 3}} \mathbf{C} \mathbf{p p m}$ & $\mathbf{J}_{\mathbf{F C}}$ & $\boldsymbol{\delta}^{\mathbf{1}} \mathbf{H} / \mathbf{p p m}$ & $\mathbf{J}_{\mathbf{H H}}$ \\
\hline $\mathrm{C}=\mathrm{O}$ & 163.5 & & \\
1 & 127.3 & & \\
2 & 130.7 & & & $\mathrm{~d}, J=1.65 \mathrm{~Hz}$ \\
3 & 136.6 & & & \\
4 & 144.0 & & 2.71 & $\mathrm{~s}$ \\
$\mathrm{CH} 3$ & 20.3 & & 7.78 & $\mathrm{~d}, J=7.9 \mathrm{~Hz}$ \\
5 & 134.2 & & 8.40 & $\mathrm{dd}, J=7.9,1.65 \mathrm{~Hz}$ \\
6 & 134.3 & & 3.34 & $\mathrm{t}, J=5.3 \mathrm{~Hz}$ \\
$2^{\prime}, 6^{\prime}$ & 42.3 & $\mathrm{t}, J=5.5 \mathrm{~Hz}$ & 2.09 & $\mathrm{~m}$ \\
$3^{\prime}, 5^{\prime}$ & 33.2 & $\mathrm{t}, J=23.2 \mathrm{~Hz}$ & & $\mathrm{dd}, J=4.1,1.4 \mathrm{~Hz}$ \\
$4^{\prime \prime}$ & 121.9 & $\mathrm{t}, J=241 \mathrm{~Hz}$ & 8.87 & $\mathrm{dd}, J=8.3,4.1 \mathrm{~Hz}$ \\
$2^{\prime \prime}$ & 150.8 & & 7.62 & $\mathrm{dd}, J=8.3,1.4 \mathrm{~Hz}$ \\
$3^{\prime \prime}$ & 122.3 & & 8.50 & $\mathrm{dd}, J=8.1,1.1 \mathrm{~Hz}$ \\
$4^{\prime \prime}$ & 136.4 & & & $\mathrm{dd}, J=8.1,7.3 \mathrm{~Hz}$ \\
$4 \mathrm{a}^{\prime \prime}$ & 129.2 & & 8.00 & $\mathrm{dd}, J=7.3,1.1 \mathrm{~Hz}$ \\
$5^{\prime \prime}$ & 126.6 & & 7.70 & \\
$6^{\prime \prime}$ & 126.5 & & & \\
$7^{\prime \prime}$ & 121.8 & & & \\
$8^{\prime \prime}$ & 146.8 & & & \\
$8 \mathrm{a}^{\prime \prime}$ & 140.2 & & &
\end{tabular}



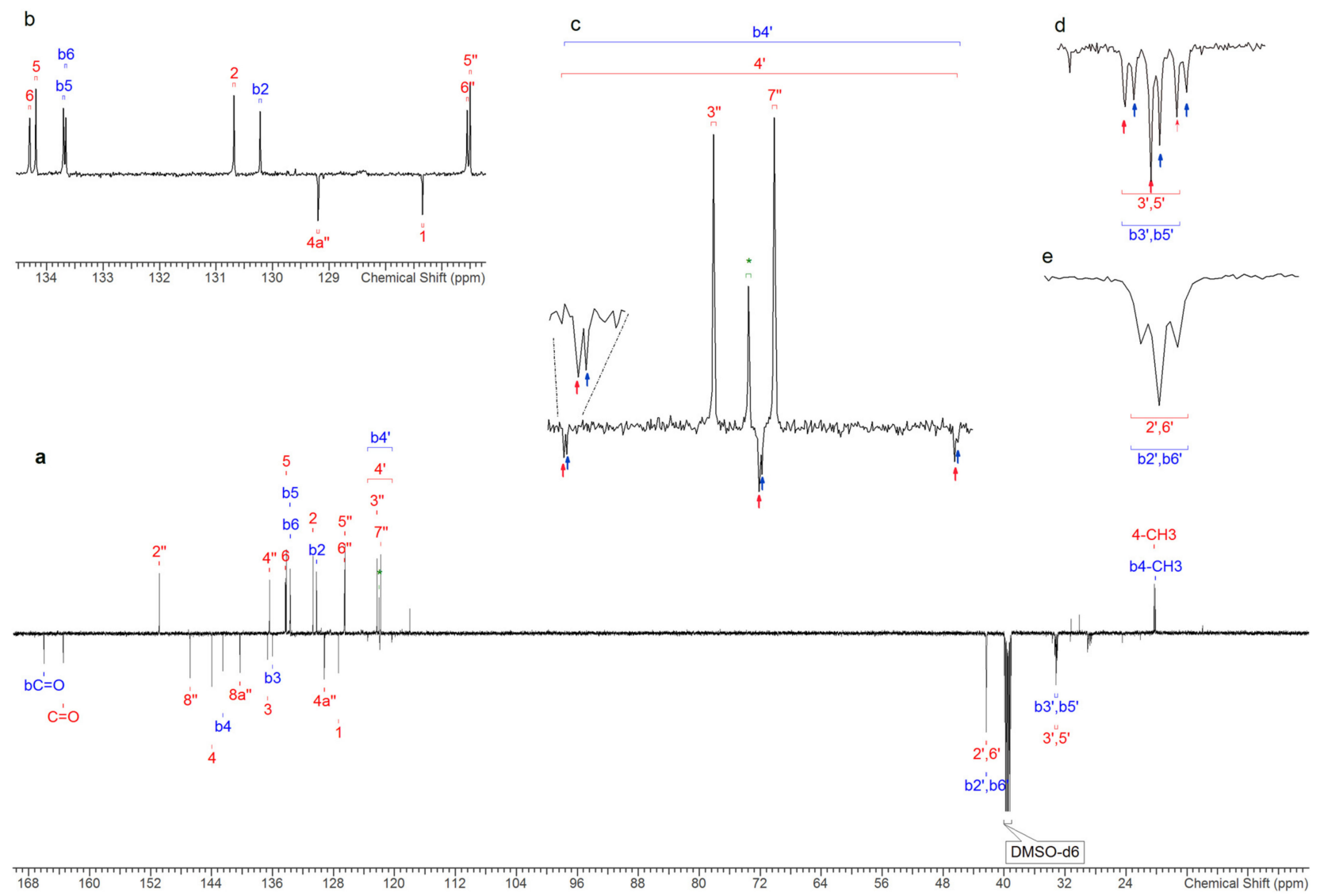

Figure 3. (a) ${ }^{13} \mathrm{C}$ APT NMR spectrum of 2F-QMPSB in DMSO- $\mathrm{d}_{6}$ (sample 7); (b) expansion of a part of the aromatic region; (c) expansions showing triplets ${ }^{1} J_{\mathrm{C}-\mathrm{F}}=241 \mathrm{~Hz}$ from carbons $4^{\prime}$ and $\mathrm{b} 4^{\prime}$ of the two identified compounds, the peak $(\delta=122 \mathrm{ppm})$ assigned with an asterisk $\left(^{*}\right)$ is from an unidentified secondary species; (d) triplets ${ }^{2} J_{\mathrm{C}-\mathrm{F}}=23.2 \mathrm{~Hz}$ of $3^{\prime}, 5^{\prime}$ and $\mathrm{b} 3^{\prime}, \mathrm{b}^{\prime}$ and (e) overlapping triplets ${ }^{3} J_{\mathrm{C}-\mathrm{F}}=5.5 \mathrm{~Hz}$ for $2^{\prime}, 6^{\prime}$ and $\mathrm{b} 2^{\prime}, \mathrm{b} 6{ }^{\prime}$.

\subsection{Chromatography and HR-MS/MS Results \\ 2.3.1. UHPLC-qTOF-MS}

An initial chromatographic screening was performed in order to assess the complexity of the analysed matrix. This assessment is essential, as it can identify possible interferents in the matrix that may affect the reliability of the results. The application of UHPLCqTOF-MS enables the chromatographic separation of all components of the sample and the subsequent production of the related $\mathrm{MS}^{\mathrm{n}}$ spectra. As there were no analytical standards available for the substances in question at the time of this work, identification was based on the spectral data followed by the application of cheminformatics tools. The MS and MS/MS data were analysed primarily with the Agilent MassHunter (Agilent Technologies, Santa Clara, CA, USA) and further processed with ACD/Labs Spectrus Processor followed by the MS Fragmenter for structural elucidation and fragmentation prediction confirmation. This software allows the prediction of fragmentation, confronting experimental with theoretical data, and annotates MS and MS/MS spectral ion trees. HR-MS/MS enables the precise determination of the monoisotopic mass and prior knowledge of the theoretical structure from the techniques employed allows the confirmation of the molecule by fragmentation matching.

It can be seen in Figure 4 that when the sample was analysed with positive ionization it was mainly composed of three substances, one of which was overwhelmingly dominant. The two additional substances showed smaller peaks with $m / z$ of $429.128\left(t_{R}=5.75 \mathrm{~min}\right)$ and $373.228\left(t_{R}=9.45 \mathrm{~min}\right.$ ), respectively (Figure 4, Figures S3 and S4). These two peaks represented only $0.5 \%$ of the relative content (based on peak areas), and for this reason 
their presence had a minimal effect on the structural elucidation of the main substance in the sample.
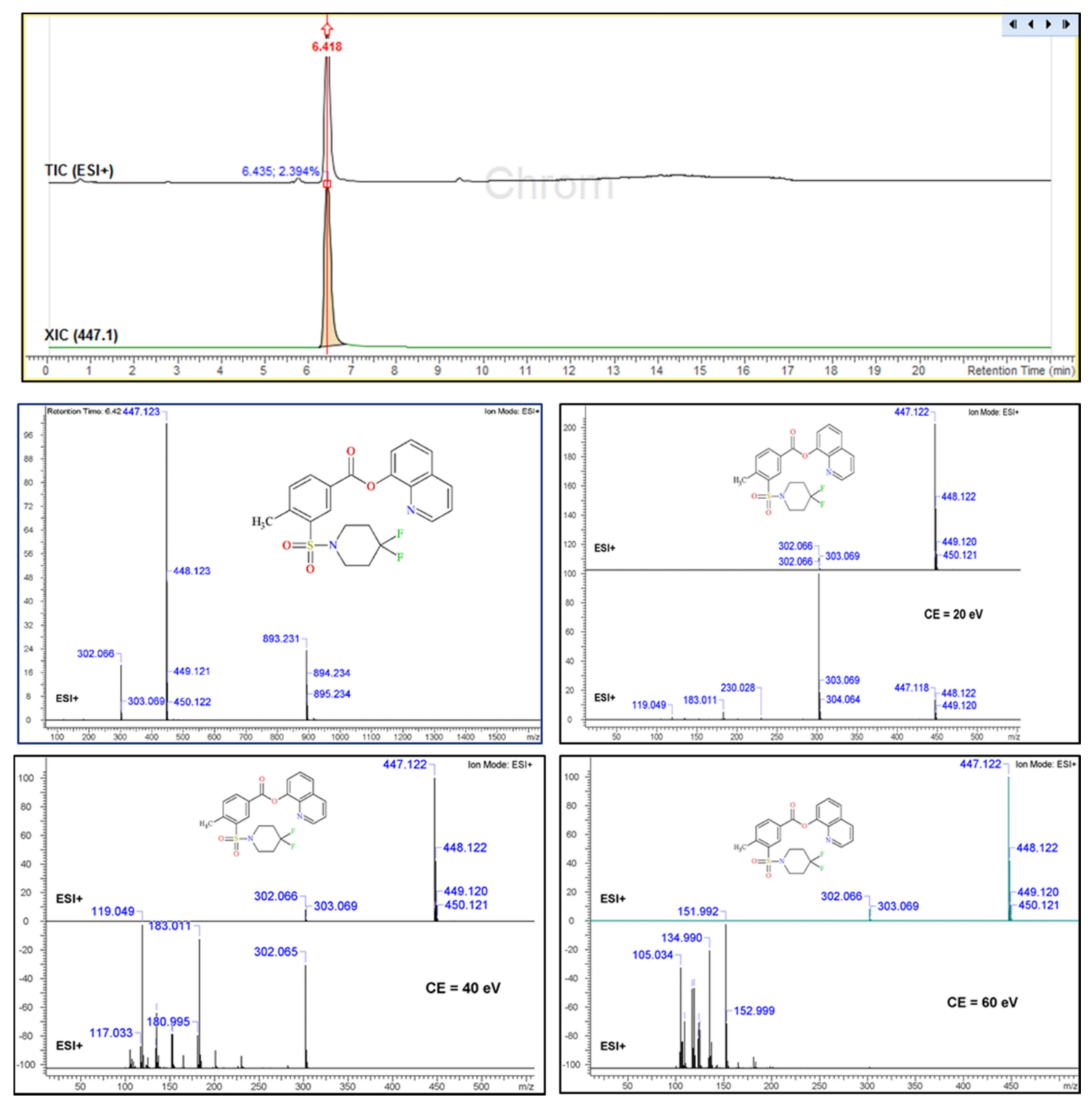

Figure 4. UHPLC-ESI(+) qTOF-MS TIC, MS and MS/MS spectra (20, 40 and $60 \mathrm{eV})$ of the identified cannabinoid 2F-QMPSB.

Regarding the main substance $\left(t_{R}=6.42 \mathrm{~min}\right)$, the full MS scan showed a base molecular ion with an $m / z$ of 447.123 , in agreement with 2F-QMPSB.

At this point it should be mentioned that the presence of a fragment with an $m / z$ of 302.066 was also noted, which was in agreement with that observed in the GC-MS analysis. This fragment seemed to be the 1-carboxy-(methylene-benzenesulfonyl)-4,4difluoropiperidinyl group (see discussion in Section 3.2) from where the oxyquinoline was detached after the cleavage of the ester bond attached to the oxyquinoline group. After performing the structural confirmation, it was most likely that this product was the result of hydrolysis of the ester bond. The presence of this fragment is most probably due to the dissolution of the extract in a mixture of acetonitrile and water, in combination with the mobile phase, which also consisted of a gradient of acetonitrile and water, in the presence of $0.1 \%$ formic acid.

Following the selection of the molecular ion $(m / z=447.123)$ an MS/MS fragmentation was performed at three selected collision energies $(\mathrm{CID}=20.0,40.0$ and $60.0 \mathrm{eV})$, to assess 
the fragmentation pattern (Figure 4). The resulting MS fragments were identified and subsequently confirmed using the ACD/Labs MS fragmenter.

The fragmentation pattern followed a specific path where the base peak $(m / z 447.123)$ was broken from the carbonyl ester bond $(m / z$ 302.066) and also in the sulfonyl group $(\mathrm{m} / \mathrm{z}$ 183.011), producing the 4,4-difluoro-1-piperidinyl sulfonyl group ( see discussion in Section 3.2). The increment of the collision energy reflects the generation of various fragments which are reported in Figure 4. The fragmentation pattern of the obtained MS/MS results from the UHPLC-qTOF-MS which confirms the proposed chemical structure. Subsequent data assessment confirmed the findings of GC-IT-MS regarding the fragmentation patterns of 2F-QMPSB and the associated fragmentation pathways are presented and discussed in paragraph 3.2. These results have been further evaluated with those from the flow injection HR-Orbitrap-MS where a difference was observed between the collision energies, regarding the fragmentation of the molecular ion in the MS2 experiments, i.e., in the case of the qTOF-MS $(40 \mathrm{eV})$, which seemed to be higher than those reported with the Orbitrap-MS (25 eV).

As the GC-MS experiments depicted in Section 2.1 indicated the presence of a 2FQMPSB precursor substance, a, LC-MS analysis, using negative ionisation (ESI-), was performed (Figure 5). The results confirmed the existence of the precursor 2F-MPSBA in its acid form $(m / z$ 318.061) in the chloroform extract, which could not be seen using ESI+. The cannabinoid 2F-QMPSB $(\mathrm{m} / \mathrm{z} 445.103)$ was also present, but at a much lower abundance when compared with the analysis using positive ionisation.
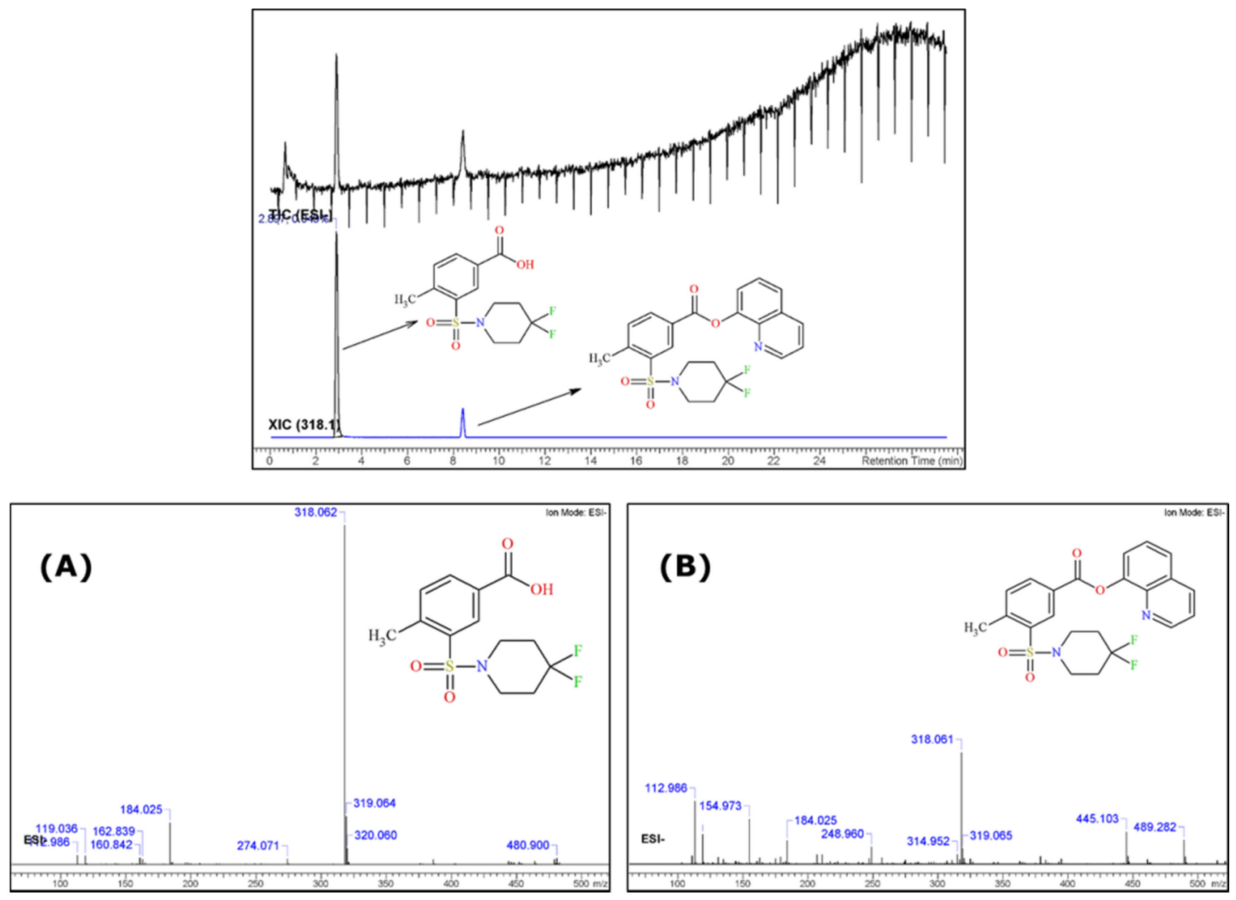

Figure 5. UHPLC-ESI (-) qTOF-MS TIC and ESI(-) MS spectra of the identified precursor 2F-MPSBA (A) and of the identified cannabinoid 2F-QMPSB (B).

\subsubsection{Flow Injection into Orbitrap MS}

In this case no hyphenated technique was applied prior to flow injection directly to the Orbitrap, where the MS resolution was 140,000 and the injection flow rate was set at $3 \mu \mathrm{L} / \mathrm{min}$. The analysis was first performed in the full scan mode, and later on the performance of $\mathrm{MS}^{2}, \mathrm{MS}^{3}$ and $\mathrm{MS}^{4}$, sequentially. The resulting $\mathrm{MS}^{\mathrm{E}}$ spectra, along with the identified fragments, are presented in Figure 6.

Full scan MS (TIC) was performed initially, where the protonated molecular ion was identified as $m / z 447.122[\mathrm{M}+\mathrm{H}]^{+}$. The TIC results are in full accordance with the results obtained with the qTOF analysis, where the existence of two ions, one at $m / z 302.068$ and a 
less abundant one at $m / z$ 183.012, could be observed indicating the hydrolysis of the ester bond as well the breakage of the sulfonyl group.


Figure 6. Flow injection Orbitrap MS and $\mathrm{MS}^{\mathrm{E}}$ spectra of the target analyte 2F-QMPSB.

For the $\mathrm{MS}^{2}$, the aforementioned molecular ion $(\mathrm{m} / z$ 447.120) was selected to be fragmented, while for the $\mathrm{MS}^{3}$ the ions $m / z 302.068$ and $m / z$ 230.030, representing the fragment (Figure 7B) with the open piperidine structure, were further investigated in the $\mathrm{MS}^{4}$ experiment. The fragmentation pattern, collision energies and $\mathrm{MS}^{\mathrm{E}}$ identified fragments are in accordance with the UHPLC-qTOF-MS experiments and with the proposed chemical structure. In addition, the evaluation of the Orbitrap-MS results demonstrated the alignment between the initial findings with GC-IT-MS and those of the qTOF-MS, regarding the spectral data of the NPS 2F-QMPSB.

\section{Discussion}

\subsection{NMR}

The ${ }^{1} \mathrm{H}$ and ${ }^{13} \mathrm{C}$ chemical shifts and $J$ coupling constants, measured in DMSO- $\mathrm{d}_{6}$ (Table 1), are in accordance with those found by Blakey, et al., and Uchiyama, et al. [9,24], for a molecule that is very similar in structure to QMPSB, The only difference observed between these two molecules was due to the presence of two fluorine atoms which were observed in the piperidinyl group, as shown in Figure 3.

Similarly, considering the chemical shift data listed in Table 1, this difference can be seen in the ${ }^{13} \mathrm{C}-\mathrm{NMR}$ spectrum for the carbon atom at position $4^{\prime}$ (Figure 3), where the two hydrogen atoms are substituted by fluorine atoms. In the ${ }^{1} \mathrm{H}-\mathrm{NMR}$ spectrum, the difference is found mainly in the protons linked to the carbons at positions $2^{\prime}, 6^{\prime}$ and $3^{\prime}, 5^{\prime}$ of the piperidinyl group.

Furthermore, the coupling constants (Table 1) are also in accordance with those reported [9] apart from those which were generated by the coupling with the two fluorine atoms bonded to the quaternary carbon $4^{\prime}$. This is clearly revealed in the ${ }^{13} \mathrm{C}$ spectrum where coupling $\left({ }^{13} \mathrm{C}\right.$ and ${ }^{19} \mathrm{~F}$ have spins of $\left.\frac{1}{2}\right)$ gives a triplet with a ${ }^{1} J_{\mathrm{CF}}$ coupling constant of $241.9 \mathrm{~Hz}$. We observed a similar splitting phenomenon of the carbon signals $3^{\prime}, 5^{\prime}$ $\left(\mathrm{t},{ }^{2} J_{\mathrm{CF}}=23.7 \mathrm{~Hz}\right)$ and $2^{\prime}, 6^{\prime}\left(\mathrm{t},{ }^{3} J_{\mathrm{CF}}=5.5 \mathrm{~Hz}\right)$. 
The $J_{C F}$ coupling constants are in line with those found in the literature, in particular with those of Jeffries, et al. and Doddrell, et al. [25,26]. The latter presented the behaviour of 1,1-difluorocyclohexane, provided that the chair-chair interconversion could be halted. The molecular dynamics of 1,1-difluorocyclohexane, where the $J_{\mathrm{CF}}$ coupling constants are ${ }^{1} J_{C F}=242 \mathrm{~Hz}$ the ${ }^{2} J_{\mathrm{CF}}=24.0 \mathrm{~Hz}$ and ${ }^{3} J_{\mathrm{CF}}=4.7 \mathrm{~Hz}$, assigned to C-1 (attached to the two fluorine atoms), C-2, and C-3, respectively [26]. Jeffries, et al. presented the synthesis of molecules bearing the 4,4-difluoropiperidine scaffold and NMR data of the 4,4-difluoropiperidine moiety which are consistent with those presented in this paper [25] as well as being in accordance with studies carried out by Yousif and Roberts [27], and Edzes, et al. and Furuya, et al. for gem-difluorides [28,29].

The monodimensional fluorine spectrum and the bidimensional spectra, confirm the proposed structure and are presented in the Supplementary Materials (Table S2 and Figures S5-S14). The NMR spectra measured in $\mathrm{CDCl}_{3}$ confirm that which was observed in the DMSO- $\mathrm{d}_{6}$ spectra. However, the signals in the aromatic region in $\mathrm{CDCl}_{3}$ are less well separated than in DMSO- $\mathrm{d}_{6}$, whereas those in the aliphatic region, in particular for the ${ }^{1} \mathrm{H}$ signals of $2^{\prime}, 6^{\prime}$ and $b 2^{\prime}, b 6^{\prime}$, are better defined as they are not overlapped by the water signal (Figures S5 and S6).

\subsection{Fragmentation Patterns by EI+ and ESI+}

Figure 7 presents the suggested fragmentation scheme, independent of the applied EI+ or ESI+ MS detection, for all the identified and confirmed fragments of 2F-QMPSB.

The additional reported substance in the GC-MS analysis was found to be the gemfluorine substituted MMPSB (2F-MMPSB; Figure 1A,B), obtained as the methyl ester derivative of its acid form 2F-MPSBA after extraction from the herbal material matrix with methanol. When chloroform was used for extraction from the same material, the peak of the precursor molecule is not present, as no transesterification with methanol occurs during extraction. The precursor remains in its acid form, which is not observable on a DB5-MS analytical column (Figure 1B). Blakey, et al. [9], reported a similar $m / z$ of 149 for MMPSB [4-methyl-3-(1-piperidinylsul-fonyl) benzoate]. The $m / z 121$ fragment was also observed, which refers to the fragmented 4,4-difluoropiperidine coming from the cleavage of the methylated 2F-MPSBA and is also consistent with the GC-MS results reported by Blakey, et al. [9]. The existence of this precursor compound was further confirmed by UHPLC-qTOF-MS analysis, where it could be identified but only in the ESI-mode (acid form). All identification results of the unknown peak in GC-MS and qTOF-MS, have been checked and confirmed by ACD/Labs data platform.

Regarding the MS of the newly identified cannabinoid, the base fragment was at $m / z 302$, representing the acylium ion arising from the cleavage of the 8-hydroxyquinoline group (Figure 7A) [30]. Another identified fragment was at $m / z 183$, representing the 4,4difluoro-1-piperidinylsulfonyl unit (Figure 7A). In addition, certain structurally rearranged peaks were identified and subsequently assessed and evaluated with the UHPLC-qTOF-MS and the Orbitrap MS.

In the LC-qTOF-MS (ESI+) TIC analysis of the chloroform extract only three peaks were observed, as shown in Figure 4, Figures S3 and S4. The most abundant one (around 98\%, based on the area normalization approach) corresponded to 2F-QMPSB. The two remaining peaks were evaluated using the cheminformatics platform, with the first one having an $m / z$ of 429.128 and possibly representing the monofluorinated QMPSB (Figure S3). It can be speculated that this was formed either due to the removal of fluorine from the piperidine group or due to a left-over compound arising from the chemical synthesis of the target molecule. The second peak presented a $m / z$ of 373.228 (Figure S4), which after processing of the spectrum with ACD/Labs was tentatively identified as a possible trace of the synthetic cannabinoid MAM-2201, as reported by Blakey, et al. [9].

An interesting observation, coming mainly from the qTOF-MS and Orbitrap-MS fragmentation results (not so clear in the GC-MS results), was the formation of an intermediate arylsulfinamide $(m / z 169)$ from the main arylsulfonamide $(m / z 183)$. This is due to the 
polarization of the C-S bonds, which appears to be very important for $\mathrm{SO}_{2}$ rearrangement, as previously reported, where during ionisation the positive charge of the protonated molecule most likely resides on the $\mathrm{S}=\mathrm{O}$ group [31,32]. 


\section{EI}

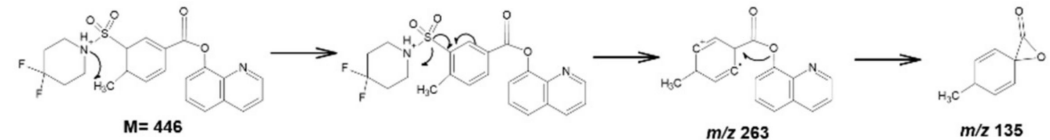

$\longrightarrow$

$M=446$

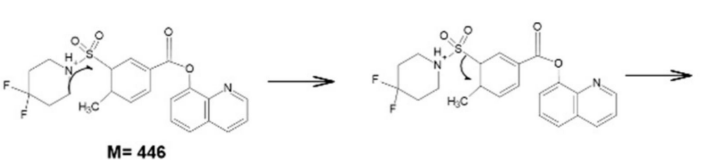

$M=446$

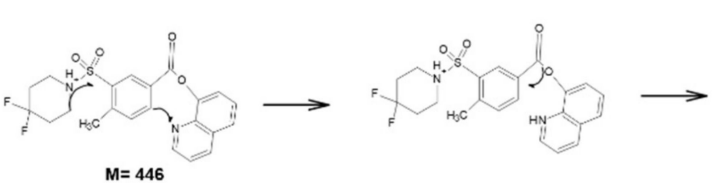

$M=446$$$
m / z 263
$$

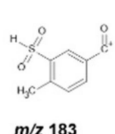

$m / z 183$

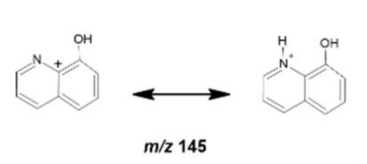

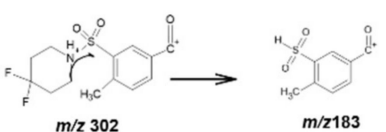

(A)



| Loss of HCN

m/z 116

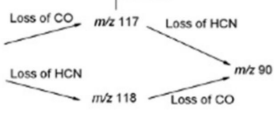

(OH

ESI
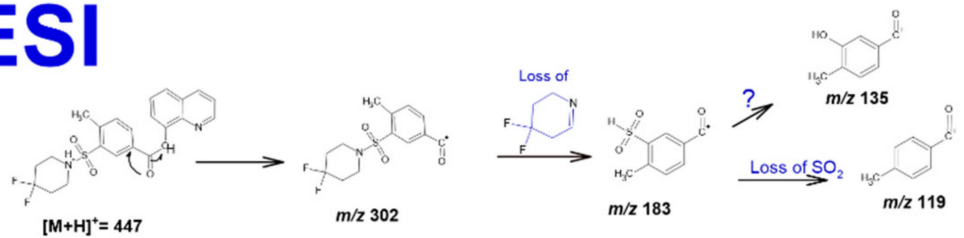

(B)

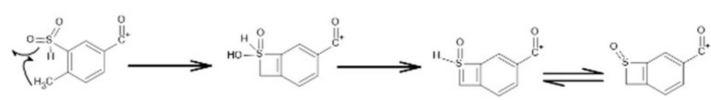

m/z 165
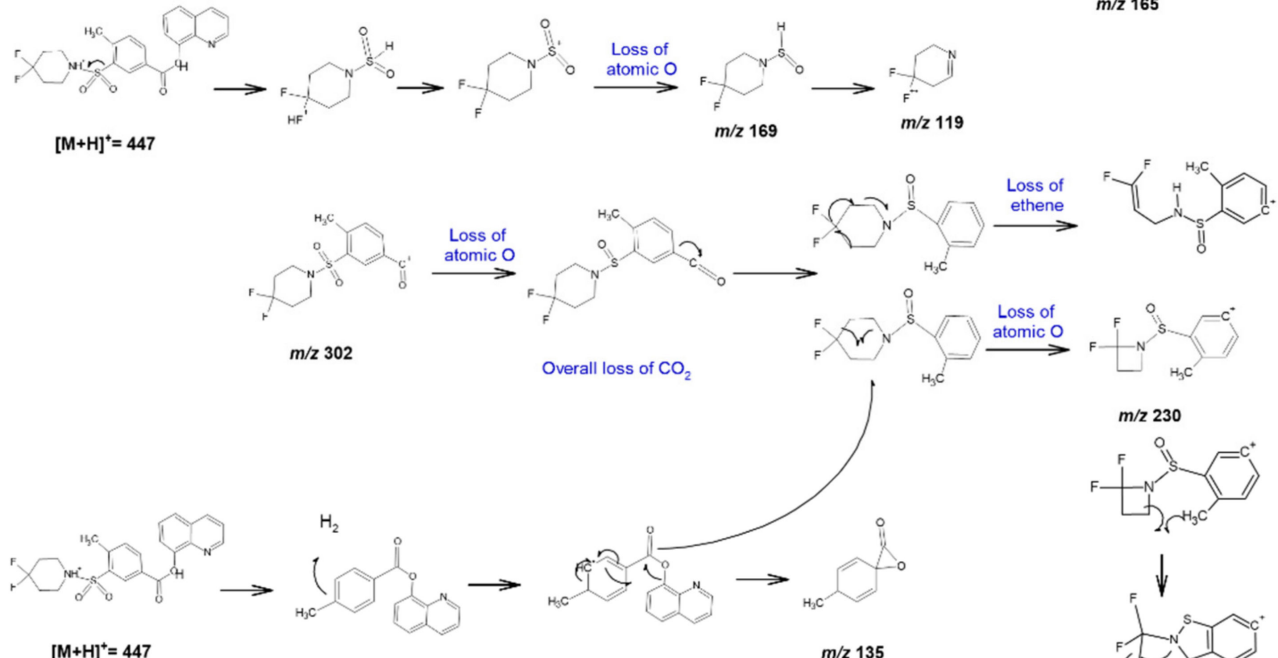

$[M+H]^{+}=447$

$m / 2135$

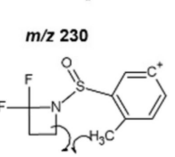

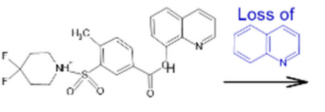

$[M+H]^{+}=\mathbf{4 4 7}$

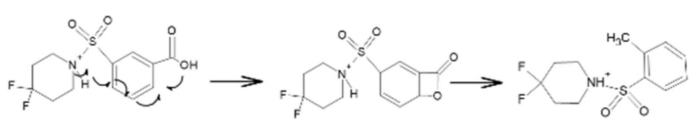

$\mathrm{m} / \mathbf{z} 201$



$\downarrow$

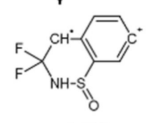

Figure 7. GC-EI-MS (A) and UHPLC-ESI HR-MS (B) suggested fragmentation schemes for identified NPS 2F-QMPSB.

The formation of arylsulfinamide, or the elimination of the $\mathrm{SO}_{2}$, could be enhanced by neighboring group participation, such as the N-S (Figure 7B). It should also be highlighted that the $\mathrm{SO}_{2}$ rearrangement pathway, in the positive mode, is less predictable [31,32]. 


\subsection{Final Considerations on the $2 F-Q M P S B$}

The work described in this manuscript represents the process involved in the first chemical identification of 2F-QMPSB, in seized samples, which led to its reporting to the EU Early Warning System [23]. At the moment of this first identification, a search for that chemical structure was performed which led only to a record found only in the PiHKAL isomer-design Website, where it was presented with the common name of 'SGT 13' [33]. Discussions about SGT-13 were found on social media where its correct IUPAC chemical name was cited and its possible effects outlined. This was found interesting because this substance does not belong to the typical category of the synthetic cannabinoids based on the indole or indazole core group, which are the more popular among drug users. After further investigation regarding the possible origin of this name, we also found a patent by Bowden and Williamson, related to a series of indole and indazole cannabinoid compounds [34]. However, SGT-13 and its corresponding chemical structure were not described in this patent. On the other hand, another patent from 2007 on novel sulfamoyl benzamide compounds, proposed that they may act as as agonists or antagonists of the cannabinoid receptor system [35]. This was experimentally confirmed by studies of some such compounds and in particular QMPSB $[12,13]$. However, it seems that until now only a few detections of these compounds were found in seized materials of recreational drugs. A recent publication reports the recent emergence of such sulfamoyl benzoate, sulfamoyl benzamide, and $N$-benzoylpiperidine based structures [36].

\section{Materials and Methods}

\subsection{Chemicals and Reagents}

All solvents used for LC-HR-MS/MS analysis, obtained from Sigma-Aldrich (Milan, Italy) were LC-MS Chromasolv grade. Ultrapure water (18.2 M $\Omega$ ) was obtained from a Milli-Q system (Millipore, Burlington, MA, USA). Deuterated dimethylsulfoxide (DMSOd6) and deuterated chloroform $\left(\mathrm{CDCl}_{3}\right)$ were $>99.8 \%$ deuterated and were also obtained from Sigma-Aldrich.

A parcel, destined for an Italian address, was seized in February 2018 from a postal shipment coming from Spain, by the Customs Officials and the Finance Guard of Malpensa Airport in Italy. Its contents were declared as "environment perfumers/ herbal incense", and it was made up of nine unlabeled transparent plastic vials containing an oily strawyellow liquid and eight plastic bags of herbal material. All samples were analyzed by GC-IT-MS at the customs laboratory in Milan, which identified several known synthetic cannabinoids in the methanol extract of the oily liquid samples and in five of these the herbal material samples. For three of the unlabeled plastic bags (samples 7, 8, and 9 of the present work), the GC-IT-MS analyses showed various concentrations of the same unkown substance with no match in the mass spectrometry libraries. Aliquots of these three samples were sent for further analysis to the JRC.

\subsection{Sample Preparation}

For the GC-IT-MS analysis, approximately $300-500 \mathrm{mg}$ of the herbal material was placed in a glass tube with $10 \mathrm{~mL}$ of methanol, sonicated for $15 \mathrm{~min}$ and filtered with a PTFE $0.22 \mu \mathrm{m}$ filter. An aliquot was then injected in the GC-MS system.

For the analysis performed at the JRC, a similar extraction procedure was employed, but with $3 \mathrm{~mL}$ of deuterated chloroform $\left(\mathrm{CDCl}_{3}\right)$ as the solvent. An amount of $650 \mu \mathrm{L}$ of the filtrate was then analysed directly by NMR. Another $650 \mu \mathrm{L}$ aliquot was left to evaporate to dryness and then redissolved with $650 \mu \mathrm{L}$ of deuterated DMSO- $\mathrm{d}_{6}$ for other NMR analysis with this solvent.

For HR-MS/MS, a portion of the $\mathrm{CDCl}_{3}$ extracts was first diluted 1:5 $v / v$ with acetonitrile, and then further diluted with a solution of 1:1 $v / v$ acetonitrile: $\mathrm{H}_{2} \mathrm{O}$. The final sample had a concentration of around $2 \mathrm{mg} / \mathrm{mL}$ for both the $\mathrm{LC}$ and the direct infusion HR-Orbitrap-MS analysis. 


\subsection{Instrumental Analysis}

The methods and analytical techniques are already described in several previous works and in references therein $[6,21,37]$.

\subsubsection{GC-MS}

A Varian 4000 Gas Chromatograph (Varian, Palo Alto, CA, USA) equipped with an Ion Trap Mass Detector (GC-IT-MS) was used in the Italian Customs Laboratory (Milan). The GC column used was a DB5-MS from Agilent Technologies $(30 \mathrm{~m}, 0.250 \mathrm{~mm}, 0.25 \mathrm{~mm}$ ) with helium as the carrier gas $(1 \mathrm{~mL} / \mathrm{min})$. The temperature program used was as follows: $2 \mathrm{~min}$ isothermal at $220^{\circ} \mathrm{C}$, ramp at $8{ }^{\circ} \mathrm{C} / \mathrm{min}$ up to $300{ }^{\circ} \mathrm{C}$ and isothermic for $15 \mathrm{~min}$ (total run time $27 \mathrm{~min}$ ). An injection volume of $1 \mu \mathrm{L}$ in split mode (80:1) and injector at $290^{\circ} \mathrm{C}$ have been used. Scan mode was used ranging from $m / z 40$ to 450 .

At the JRC, an Agilent 7890, equipped with a 5975C MSD detector, was used with the same settings and conditions of analysis as described above for the Italian customs laboratory.

\subsubsection{NMR}

Spectra were acquired on a Bruker (Rheinstetten, Germany) spectrometer Avance III HD 600 (nominal proton frequency $600.13 \mathrm{MHz}$ ), equipped with a $5 \mathrm{~mm}$ QCI cryo-probe $\left({ }^{1} \mathrm{H},{ }^{13} \mathrm{C},{ }^{15} \mathrm{~N}\right.$ and $\left.{ }^{19} \mathrm{~F}\right)$, in DMSO- $\mathrm{d}_{6}$ and $\mathrm{CDCl}_{3}$ solvent at $295 \mathrm{~K}$ and $300 \mathrm{~K}$, respectively. ${ }^{1} \mathrm{H}$ and ${ }^{13} \mathrm{C}$ NMR chemical shifts are expressed in $\delta$ scale (ppm) and referenced to the solvent residuals, at $2.50 \mathrm{ppm}$ and $39.52 \mathrm{ppm}$ respectively for DMSO- $\mathrm{d}_{6}$ or $7.23 \mathrm{ppm}$ and $77.0 \mathrm{ppm}$ for $\mathrm{CDCl}_{3}$.

\subsubsection{HR-MS/MS}

- $\quad$ UHPLC-qTOF-MS analysis

A UHPLC system (Agilent 1290) with a qTOF-MS (Agilent 6540 UHD Accurate-Mass, Agilent, Waldbronn, Germany), with ESI+ $(4 \mathrm{kV})$ and ESI- $(-3 \mathrm{kV})$ ionization modes, were used. The source temperature was $325^{\circ} \mathrm{C}$. Nitrogen was used as both the drying (40 psi) and nebulizing gas (10 L min-1). The injection volume was $5 \mu \mathrm{L}$. The TOF-MS detector was set for a $m / z$ range of 100-1600, with acquisition of MS/MS high resolution accurate mass data. The fragmentation collision energies for the ESI (+) ranged from 5-60 eV.

A Waters (Waters, Milford, MA, USA) BEH C18 $(100 \times 2.1 \mathrm{~mm}, 1.7 \mu \mathrm{m})$ analytical column was used at $40{ }^{\circ} \mathrm{C}$. The mobile phase (flow rate: $200 \mu \mathrm{L} \mathrm{min}{ }^{-1}$ ) consisted of water (A) and methanol (B), both with $0.1 \%$ formic acid. The gradient program changed linearly from $50 \%$ to $95 \%$ (B) in $25 \mathrm{~min}$, followed by an isocratic elution for $4 \mathrm{~min}$ and an equilibration time of $1 \mathrm{~min}$ to reach initial mobile phase conditions.

- $\quad$ Direct infusion to Orbitrap-MS

Thermo LTQ Orbitrap MS (Thermo Scientific, Bremen, Germany). Analysis was performed with ESI+ operated with mass resolution of 140,000 at $m / z 400$. The chloroform extracts of the herbal material were first diluted in pure acetonitrile, followed by another dilution with $\mathrm{H}_{2} \mathrm{O}$ to have a final 1:1 $v / v$ ratio. The resulting samples were then infused at a flow rate of $5 \mu \mathrm{L} / \mathrm{min}$ on the system.

\subsection{Cheminformatics}

The ACD/Labs suite (ACD/Labs, Toronto, ON, Canada) was used, together with MassHunter (Agilent Technologies) and XCalibur (Thermo Scientific) to assess and evaluate the relevant data for structural elucidation of the substances under investigation.

\section{Conclusions}

New synthetic cannabimimetic substances are reaching the European illicit drugs market and posing considerable challenges to both customs and control laboratories re- 
garding their identification and subsequent control. This underlines the need for new and systematic analytical approaches such as the one outlined in this study.

The identification of NPS remains challenging and although GC-MS is a powerful detection tool, additional techniques, such as those detailed here, are required for the absolute analytical confirmation of new substances. In the present work, the combination of HR-MS, NMR and cheminformatics techniques proved effective in the structural elucidation of the new synthetic cannabinoid quinolin-8-yl-3-[(4,4-difluoropiperidin-1-yl) sulfonyl]-4-methylbenzoate (2F-QMPSB), the identification of which is reported here for the first time. It was also possible to identify the presence of an acid precursor of 2F-QMPSB, the 4-methyl-3-(4,4-difluoro-1-piperidinylsulfonyl) benzoic acid (2F-MPSBA).

Supplementary Materials: The supplementary materials are available online.

Author Contributions: Conceptualisation, E.D.T., J.A.L., M.V.H., F.R., C.G.; investigation and experimental analysis, E.D.T., J.A.L., M.V.H., F.R., G.P.; writing-original draft, E.D.T., J.A.L.; revision and experimental follow-ups: E.D.T., J.A.L., M.V.H., F.R., G.P., C.G.; visualisation and final revision: E.D.T., J.A.L., M.V.H., F.R., C.G. All authors have read and agreed to the published version of the manuscript.

Funding: This research was funded by European Commission Directorate General for Taxation and Customs Unions (DG TAXUD) for the administrative and financial support provided to the JRC through the Administrative Arrangement CLEN2SAND II (JRC-Nr 34606-DG TAXUD-Nr TAXUD/2016/DE/331).

Institutional Review Board Statement: Not applicable.

Informed Consent Statement: Not applicable.

Data Availability Statement: Electronic data can be available upon request to the corresponding authors.

Acknowledgments: Davide Tanzarella (Malpensa Customs, Antifraud Office), Luigi Pardi, Carlo Alberto Zambito and Francesco Fatiga (Guardia di Finanza Malpensa Airport) are acknowledged for the seizing of the samples. We are grateful to Hendrik Emons (JRC) for reviewing this manuscript.

Conflicts of Interest: The authors declare no conflict of interest.

Disclaimer: Certain commercial equipment, instruments, and materials are identified in this paper/report to specify adequately the experimental procedure. In no case does such identification imply recommendation or endorsement by the European Commission, nor does it imply that the material or equipment is necessarily the best available for the purpose.

Sample Availability: Samples of the compounds are not available from the authors.

\section{References}

1. Breindahl, T.; Kimergård, A.; Andreasen, M.F.; Pedersen, D.S. Identification of a new psychoactive substance in seized material: The synthetic opioid N-phenyl-N-[1-(2-phenethyl)piperidin-4-yl]prop-2-enamide (Acrylfentanyl). Drug Test. Anal. 2017,9 , 415. [CrossRef] [PubMed]

2. European Monitoring Centre for Drugs and Drug Addiction. European Drug Report 2016: Trends and Developments. 2016. Available online: http:/ / www.emcdda.europa.eu/publications/edr/trends-developments/2016_en (accessed on 19 March 2019).

3. European Monitoring Centre for Drugs and Drug Addiction. New Psychoactive Substances in Europe. An Update from the EU Early Warning System (March 2015), Publications Office of the European Union, Luxembourg. 2015. Available online: http:/ / www.emcdda.europa.eu/publications/rapid-communications/2015/new-psychoactive-substances_en (accessed on 12 March 2019).

4. Brandt, S.D.; King, L.A.; Evans-Brown, M. The new drug phenomenon: Editorial and perspective. Drug Test. Anal. 2014,6 , 587. [CrossRef] [PubMed]

5. UNODC (United Nations Office on Drug and Crime). The Challenge of New Psychoactive Substances. Available online: https:/ / www.unodc.org/documents/scientific/NPS_2013_SMART.pdf (accessed on 19 March 2019).

6. Vicente, J.L.; Chassaigne, H.; Holland, M.V.; Reniero, F.; Kolář, K.; Tirendi, S.; Vandecasteele, I.; Vinckier, I.; Guillou, C. Systematic analytical characterization of new psychoactive substances: A case study. Forensic Sci. Int. 2016, 265, 107. [CrossRef] [PubMed] 
7. Baum, R.M. New Variety of Street Drugs Poses Growing Problem: Designer drugs-Analogs of compounds with proven pharmacological activity made by underground chemists-Present novel challenges to law enforcement officials, legislators, and scientists. Chem. Eng. News 1985, 63, 7. [CrossRef]

8. Bonnet, U.; Mahler, H. Synthetische Cannabinoide: Verbreitung, Suchtbiologie \& aktuelle Perspektive der persönlichen Gesundheitsgefährdung. Fortschr. Neurol. Psychiatr. 2015, 83, 221. [CrossRef]

9. Blakey, K.; Boyd, S.; Atkinson, S.; Wolf, J.; Slottje, P.M.; Goodchild, K.; McGowan, J. Identification of the novel synthetic cannabimimetic 8-quinolinyl 4-methyl-3-(1-piperidinylsulfonyl)benzoate (QMPSB) and other designer drugs in herbal incense. Forensic Sci. Int. 2016, 260, 40. [CrossRef]

10. Lindigkeit, R.; Boehme, A.; Eiserloh, I.; Luebbecke, M.; Wiggermann, M.; Ernst, L.; Beuerle, T. Spice: A never ending story? Forensic Sci. Int. 2009, 191, 58. [CrossRef]

11. European Monitoring Centre for Drugs and Drug Addiction (EMCDDA). Understanding the Spice Phenomenon. 2010. Available online: http:/ / www.emcdda.europa.eu/publications/thematic-papers/understanding-spice-phenomenon_en (accessed on 12 March 2019).

12. Lambeng, N.; Lebon, F.; Christophe, B.; Burton, M.; de Ryck, M.; Quéré, L. Arylsulfonamides as a new class of cannabinoid CB1 receptor ligands: Identification of a lead and initial SAR studies. Bioorganic Med. Chem. Lett. 2007, 17, 272. [CrossRef]

13. Ermann, M.; Riether, D.; Walker, E.R.; Mushi, I.F.; Jenkins, J.E.; Noya-Marino, B.; Brewer, M.L.; Taylor, M.G.; Amouzegh, P.; East, S.P.; et al. Arylsulfonamide CB2 receptor agonists: SAR and optimization of CB2 selectivity. Bioorganic Med. Chem. Lett. 2008, 18, 1725. [CrossRef]

14. Dresen, S.; Ferreirós, N.; Pütz, M.; Westphal, F.; Zimmermann, R.; Auwärter, V. Monitoring of herbal mixtures potentially containing synthetic cannabinoids as psychoactive compounds. J. Mass Spectrom. 2010, 45, 1186. [CrossRef]

15. Hudson, S.; Ramsey, J. The emergence and analysis of synthetic cannabinoids. Drug Test. Anal. 2011, 3, 466. [CrossRef] [PubMed]

16. Ernst, L.; Schiebel, H.-M.; Theuring, C.; Lindigkeit, R.; Beuerle, T. Identification and characterization of JWH-122 used as new ingredient in "Spice-like" herbal incenses. Forensic Sci. Int. 2011, 208, e31. [CrossRef] [PubMed]

17. Auwärter, V.; Dresen, S.; Weinmann, W.; Müller, M.; Pütz, M.; Ferreirós, N. 'Spice' and other herbal blends: Harmless incense or cannabinoid designer drugs? J. Mass Spectrom. 2009, 44, 832. [CrossRef] [PubMed]

18. Edmunds, R.; Locos, O.; Brown, D.; Reynolds, D. Identification of the synthetic cannabinoid (1-(cyclohexylmethyl)-1H-indol-3yl)(4-methoxynaphthalen-1-yl)methanone on plant material. Microgram J. 2013, 10, 3.

19. Barratt, M.J.; Cakic, V.; Lenton, S. Patterns of synthetic cannabinoid use in Australia. Drug Alcohol Rev. 2013, 32, 141. [CrossRef] [PubMed]

20. Bruni, N.; della Pepa, C.; Oliaro-Bosso, S.; Pessione, E.; Gastaldi, D.; Dosio, F. Cannabinoid Delivery Systems for Pain and Inflammation Treatment. Molecules 2018, 23, 2478. [CrossRef]

21. Guillou, C.; Reniero, F.; Vicente, J.L.; Holland, M.; Kolar, K.; Chassaigne, H.; Tirendi, S.; Schepers, H. Collaboration of the Joint Research Centre and European Customs Laboratories for the Identification of New Psychoactive Substances. Curr. Pharm. Biotechnol. 2018, 19, 91. [CrossRef]

22. Zanzi, A.; Wittwehr, C. Searching Online Chemical Data Repositories via the ChemAgora Portal. J. Chem. Inf. Model. 2017, 57, 2905. [CrossRef]

23. European Monitoring Centre for Drugs and Drug Addiction. Quinolin-8-yl3-((4,4-Difluoropiperi din-1-yl)s Ulfonyl)-4-Methylbenzoate (2F-QMPSB); EU Early Warning System Formal Notification EU-EWS-RCS-FN-2019-0002; EMCDDA: Lisbon, Portugal, 2019.

24. Uchiyama, N.; Kawamura, M.; Kikura-Hanajiri, R.; Goda, Y. Identification of two new-type synthetic cannabinoids, N-(1adamantyl)-1-pentyl-1H-indole-3-carboxamide (APICA) and N-(1-adamantyl)-1-pentyl-1H-indazole-3-carboxamide (APINACA), and detection of five synthetic cannabinoids, AM-1220, AM-2233, AM-1241, CB-13 (CRA-13), and AM-1248, as designer drugs in illegal products. Forensic Toxicol. 2012, 30, 114. [CrossRef]

25. Jeffries, D.E.; Witt, J.O.; McCollum, A.L.; Temple, K.J.; Hurtado, M.A.; Harp, J.M.; Blobaum, A.L.; Lindsley, C.W.; Hopkins, C.R. Discovery, characterization and biological evaluation of a novel (R)-4,4-difluoropiperidine scaffold as dopamine receptor 4 (D $4 \mathrm{R}$ ) antagonists. Bioorganic Med. Chem. Lett. 2016, 26, 5757. [CrossRef]

26. Doddrell, D.; Charrier, C.; Roberts, J.D. Nuclear Magnetic Resonance Spectroscopy. A Stereospecific 3JCF Coupling in the Low-Temperature 13C Nmr Spectrum of 1,1-Difluorocyclohexane. Proc. Natl. Acad. Sci. USA 1970, 67, 1649. [CrossRef] [PubMed]

27. Yousif, G.A.; Roberts, J.D. Nuclear magnetic resonance spectroscopy. Conformational equilibria and equilibration of 4,4difluoropiperidine. Measurement of the N-H inversion rate in a six-membered ring. J. Am. Chem. Soc. 1968, 90, 6428. [CrossRef]

28. Edzes, H.T.; Peters, G.J.; Noordhuis, P.; Vermorken, J.B. Determination of the Antimetabolite Gemcitabine $\left(2^{\prime}, 2^{\prime}\right.$-Difluoro- $2^{\prime}-$ deoxycytidine) and of 2',2'-Difluoro-2'-deoxyuridine by 19F Nuclear Magnetic Resonance Spectroscopy. Anal. Biochem. 1993, 214, 25. [CrossRef]

29. Furuya, T.; Fukuhara, T.; Hara, S. Synthesis of gem-difluorides from aldehydes using DFMBA. J. Fluor. Chem. 2005, 126, 721. [CrossRef]

30. Blumenthal, T.; Gillis, R.G.; Porter, Q.N.; Yeoh, L.L. Elimination of carbon monoxide by electron impact on quinolineN-oxide, carbostyril and 8-hydroxyquinoline. Org. Mass Spectrom. 1991, 26, 247. [CrossRef]

31. Sun, M.; Dai, W.; Liu, D.Q. Fragmentation of aromatic sulfonamides in electrospray ionization mass spectrometry: Elimination of $\mathrm{SO} 2$ via rearrangement. J. Mass Spectrom. 2008, 43, 383. [CrossRef] 
32. Klagkou, K.; Pullen, F.; Harrison, M.; Organ, A.; Firth, A.; Langley, G.J. Approaches towards the automated interpretation and prediction of electrospray tandem mass spectra of non-peptidic combinatorial compounds. Rapid Commun. Mass Spectrom. 2003, 17, 1163. [CrossRef]

33. Explore SGT-13 | PiHKAL · Information. Available online: https: / / isomerdesign.com/PiHKAL/explore.php?domain=pk\&id=42 38 (accessed on 12 March 2019).

34. Bowden, M.J.; Willamson, J.P.B. Cannabinoid. Compounds. Patent WO2014167530A1, 16 October $2014 . \quad$ Available online: https:/ / patentscope.wipo.int/search/en/detail.jsf;jsessionid=C6D2AB4E889A5D7A6ACA7B639314879F.wapp2nC?docId= WO2014167530\&tab=PCTDESCRIPTION\&maxRec=1000 (accessed on 12 March 2019).

35. Dolle, R.; Worm, K. Sulfamoyl Benzamides as Cannabinoid Receptor. Modulators. Patent WO2007058960, 24 May 2007.

36. Brandt, S.D.; Kavanagh, P.V.; Westphal, F.; Dreiseitel, W.; Dowling, G.; Bowden, M.J.; Williamson, J.P.B. Synthetic Cannabinoid Receptor Agonists: Analytical Profiles and Development of QMPSB, QMMSB, QMPCB, 2F-QMPSB, QMiPSB, and SGT-233. Drug Test. Anal. 2021, 13, 175-196. [CrossRef]

37. Tsochatzis, E.; Lopes, J.A.; Reniero, F.; Holland, M.; Åberg, J.; Guillou, C. Identification of 1-Butyl-Lysergic Acid Diethylamide (1B-LSD) in Seized Blotter Paper Using an Integrated Workflow of Analytical Techniques and Chemo-Informatics. Molecules 2020, 25, 712. [CrossRef] 